\title{
An assessment of the effect of abandoned coastal wetland restoration in China- Achievements and lessons
}

\author{
Zhenglei Xie ${ }^{1,2, a^{*}}$, Zebing Du ${ }^{1, b}$, Hezi Zhang ${ }^{1, \mathrm{c}}$, Lixiong Xiang ${ }^{1, \mathrm{~d}}$, Yuli $\mathrm{Wu}^{1, \mathrm{e}}$, \\ Yinghui Jiang ${ }^{1, f}$, Xiaoxiang Zhao ${ }^{1,9}$, Shimei Li, ${ }^{3, h}$, Xiaoyang Yang ${ }^{4, i}$, Kai Shan ${ }^{5, j}$ \\ ${ }^{1}$ School of Geography \& Environment, Jiangxi Normal University, Nanchang 330022, P.R. China. \\ ${ }^{2}$ Key Laboratory of Education Ministry for Poyang Lake Wetland \& Watershed Research, Nanchang \\ 330022, P.R. China. \\ ${ }^{3}$ College of Landscape Architecture and Forestry, Qingdao Agricultural University, Qingdao 266109, \\ P.R. China. \\ ${ }^{4}$ The institute of Yellow River estuarine research, Dongying 257091, P.R. China. \\ ${ }^{5}$ Institute of Geographic Sciences and Natural Resources Research, Chinese Academy of \\ Sciences(CAS), Beijing 100101, P.R China.

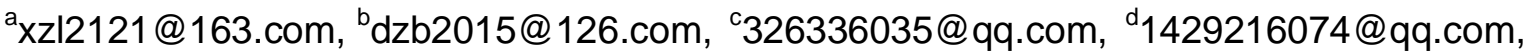

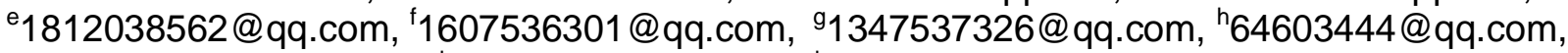 \\ '904894663@qq.com, jbbsbird@163.com.
}

\begin{abstract}
Keywords: Transfer water, abandoned estuary wetland, ecological restoration, Yellow River Delta Abstract. Estuary wetlands have been continuing to degrade under the pressures of natural factors and anthropogenic activities. The goal of restoration is to re-establish the hydrologic connection, and one of the most important methods of restoring abandoned wetlands is supplying freshwater to degraded wetlands. The decreasing Yellow River discharge and the altered flow regime during the last few decades are most likely a factor responsible for problems related to ecosystem deterioration, habitat loss, siltation of the river channel, groundwater depletion, and an increase in soil salinity. The Yellow River Conservancy Commission conducted water transfer engineering during the $10^{\text {th }}$ flow-sediment regulation regime in the flood season of July, 2010. The water transferring project has resulted in significant positive ecological effects, including increased areas of freshwater wetlands, changes in vegetation types and bird diversity. The endangered species of red-crowned crane has increased by 11 and by 19 in 2010 and 2011, respectively, and the oriental white stork has increased by 18 , suggesting the improved effects of Diaokou wetland ecological water transfer. It is necessary to establish a mechanism for the periodic monitoring of wetland resources. Coastal ecosystem degradation has led to the diagnosis, a restoration process, and an after-the-fact assessment, showing that adaptive management should be used in the practice of coastal ecosystem restoration. Therefore, future studies should incorporate water quality parameters to compare different restoration scenarios in achieving watershed-scale management goals.
\end{abstract}

\section{Introduction}

Wetlands provide important hydrologic, geochemical, environmental, and biological functions in a watershed and play an important role in controlling soil erosion and alleviating pollution (Wang et al., 2014; Elliott et al., 2007). Coastal ecosystems are under ever-increasing pressure from anthropogenic activities associated with the rapid economic, social, and industrial development (Naser, 2015; Paalvast and van der Velde, 2014; Qiu et al., 2009; Xie et al., 2012). Human activities, such as land reclamation, dredging, and sea enclosing have had destructive impacts on estuarine ecosystems (Chen et al., 2012; Lai et al., 2015; Koh and de Jonge, 2014). One of the principal strategies used to minimise anthropogenic pressures and to conserve marine biodiversity and habitats is the establishment of marine protected areas (MPAs) (Ruiz-Frau et al., 2015). Establishing MPAs as the management tools to achieve global marine conservation targets is simple and economical and adheres to the precautionary principle, ecosystem-based management, and habitat protection before species conservation guidelines (Chen et al., 2015; Bermas-Atrigenio and Chua, 2013). 
The restoration and management of the estuarine ecosystem has mainly been a national issue. The effective restoration of damaged and degraded wetlands through adaptive management is urgent (Mitsch and Day, 2006; Aldous et al., 2005; Cui et al., 2009). Hydrology is one of the most critical factors that influences the structure and function of wetlands during the restoration process (Yang et al., 2013; Morandi et al., 2014; Kristensen et al., 2014). Lai et al. (2015) found that the resulting loss of natural shores and the gain in artificial ones has profound implications for the conservation of marine ecosystems and species in urban settings. The Mississippi-Ohio-Missouri River Basin, Louisiana Coastal Protection and Restoration Authority (CPRA) and the Florida Everglades restorations are mostly hydrologic engineering projects (Mitsch and Day, 2006). Day et al. (2012) indicated that the wetland loss in the Mississippi Delta is an ongoing complex process involving several interacting factors, and the efforts to create and restore Louisiana's estuarine wetlands must emphasize riverine inputs of fresh water and sediment. Leeds et al. (2009) concluded that supplying water to over-drained wetlands can impact soil nutrients and vegetation. The Chinese government has launched a series of restoration programs to conserve coastal ecosystems through the transfer of fresh water into degraded wetlands (You et al., 2009; Cui et al., 2009; Luo et al., 2015; Jones and Hanna, 2004). Supplying fresh water has been shown to be an effective method to help reconstruct degraded estuary wetlands that have been subjected to drainage and saltwater intrusion (Wang et al., 2011; Craft, 2007; Theriot et al., 2013; Zhai et al., 2010; Hu et al., 2008).

The Yellow River Delta (YRD) is one of the most active areas of land-ocean interaction among the large river deltas in the world and is the largest wetland ecosystem in the warm temperature zone of China (Cui et al., 2009). The hydrological characteristics of estuarine wetlands are affected by the interactions between freshwater and seawater. The decreasing YR discharge and the altered flow regime during the last few decades are the most likely factors responsible for problems related to ecosystem deterioration, habitat evanescence, siltation of the river channel, groundwater depletion, and soil salinity increase (Cui et al., 2009). Due to a lack of fresh water and sand supply resulting from industrial and agricultural development and tidal intrusion, the seawater continued to intrude, and the coastal line retreated substantially (Xie et al., 2014; Luo et al., 2015). A restoration project was implemented in the YRD Natural Reserve (YRDNR) in July 2002 to reintroduce fresh water from the river to these degraded wetlands (Xie et al., 2014). The effects of wetland restoration are commonly evaluated by analysing changes in the hydrology, biophysical components, and chemical properties of the soil. Changes in soil properties and plant community biomass were evaluated by comparing sites with freshwater treatment versus reference sites following the addition of fresh water to wetlands of the YRD Qingshuigou flow path (Wang et al. 2011). A monitoring program was implemented in the YRD study areas to measure indicators before and after restoration in 2001. Water quality, soil salinity, soil organic matter, plant community, and bird species were chosen as indicators in this program. The degraded wetland restoration project was implemented in the Diaokou flow path YRDNR in July 2010 to reintroduce freshwater from the YR to degraded wetlands. The goal of this management effort was to reduce the soil salinization, which is the primary threat to freshwater wetlands, providing suitable habitats for freshwater vegetation and faunal species, especially waterfowl. Huang et al. (2012) applied HJ-1 micro satellite remote sensing data to monitor and evaluate the effectiveness of wetland restoration in the YRD water transfer project. The results showed that the flow conditions of the former abandoned channel were greatly improved through water transfer from the YR. However, previous studies only focusing on eutrophic water restoration effects in lakes and the effects of coastal ecosystems remain poorly understood, and little research has been conducted to quantify these changes and their impacts.

By designing future restoration according to ecological principles, these structures may eventually host a greater diversity of native coastal species and hence contribute to conservation management plans. The specific objective of this study is to (1) select the Diaokou flow path to assess the coastal restoration effect through transferring freshwater to wetlands in YRD, and summarise the method and process of abandoned estuarine wetlands, and (2) to provide detailed guidelines for land use management. Achievements and lessons are also provided from the restoration effort to give suggestions for other coastal ecosystem restoration activities in China. We also evaluated the 
environmental problems arising from restoration, highlighting the potential to incorporate ecological engineering.

\section{Study Area}

The YRDNR $\left(37^{\circ} 35^{\prime}-38^{\circ} 12^{\prime} \mathrm{N}, 118^{\circ} 33^{\prime}-119^{\circ} 20^{\prime} \mathrm{E}\right)$ is located on the estuary of the YR near Dongying City, Shandong Province, eastern China. The YRDNR is characterized by a temperate continental monsoon climate with distinct seasons. It has warm temperate continental monsoon climate with distinctive seasons and rainy summer (Cui et al., 2009). The mean annual temperature across the region is $12.2^{\circ} \mathrm{C}$, ranging from $41^{\circ} \mathrm{C}$ in July to $-22^{\circ} \mathrm{C}$ in January. Mean annual precipitation is $600 \mathrm{~mm}$, with a mean annual relative humidity of $68 \%$ (Yang et al., 2013). The YRDNR is a kind of new-born wetland ecosystem nature reserve, featured by youth, frangibility, and instability (Fig 1). In 1992, the State Council has approved the establishment of national natural reserve to protect the newly created estuarine wetland and endangered waterfowl (Wang et al., 2011). The NR consists of two separate parts: the Diaokou NR (north, $485 \mathrm{~km}^{2}$ ) and the YR Mouth NR (south, $1045 \mathrm{~km}^{2}$ ). The length flow path of Diaokou is $55 \mathrm{~km}$ and is located in the north part of the YRD and is the river channel between Jan, 1964 and May, 1976. The water amount of $518.07 \times 10^{6} \mathrm{~m}^{3}$ and the sediment are $13.496 \times 10^{6}$ ton and created the land of $507 \mathrm{~km}^{2}$ and the coastal line has expanded $1.4 \mathrm{~km}$. The length of flow path has increased from $26 \mathrm{~km}$ in the 1964 to $64 \mathrm{~km}$ in 1976 (Li et al., 2009). The Diaokou flow path was ever connected with the sea, but the intensive anthropogenic activities for reclamation and petroleum development in the past decades changed the feature of the river (Cui et al., 2009). While the ecological condition of Diaokou flow path has degraded owing to the cut down of the river since May, 1976. YRD is a famous oil production base in China which has undergone major road construction between the river and wetlands. Shengli Oilfield established 10 production oil areas and standard protective levee to withstand the flood, chemical factory, farmland, plant base in the flow path area and constructed plenty of oil-gas exploration production facilities, power, communication, hydrologic, and other logistics facilities. The Dongying government has established the preparation office of Dongying port-vicinity industrial park and the planned urban areas is $120 \mathrm{~km}^{2}$. Water supply to the wetland was stopped due to these road constructions and natural hydrological relationships between the river and its floodplain were seriously destroyed (Cui et al., 2009). There are more than 800 animal species, consisting of 199 kinds of birds: 7 of them are first-class protection bird species defined by the government such as red-crowned crane (Grus japonensis) and oriental white stork (Ciconia boyciana), as well as 31 second-class protection bird species. Suaeda salsa community, Tamarix chinensis community and Phragmites communis community are dominant plant communities established during the natural vegetation succession. Wetland ecosystems provide the birds with habitats for breeding, migrating and wintering, making the region an important over-wintering in the inland of North-Eastern Asia Inland and around the Western Pacific Ocean Rim flyway for bird migration, including endangered red crane (Cui et al., 2009). 


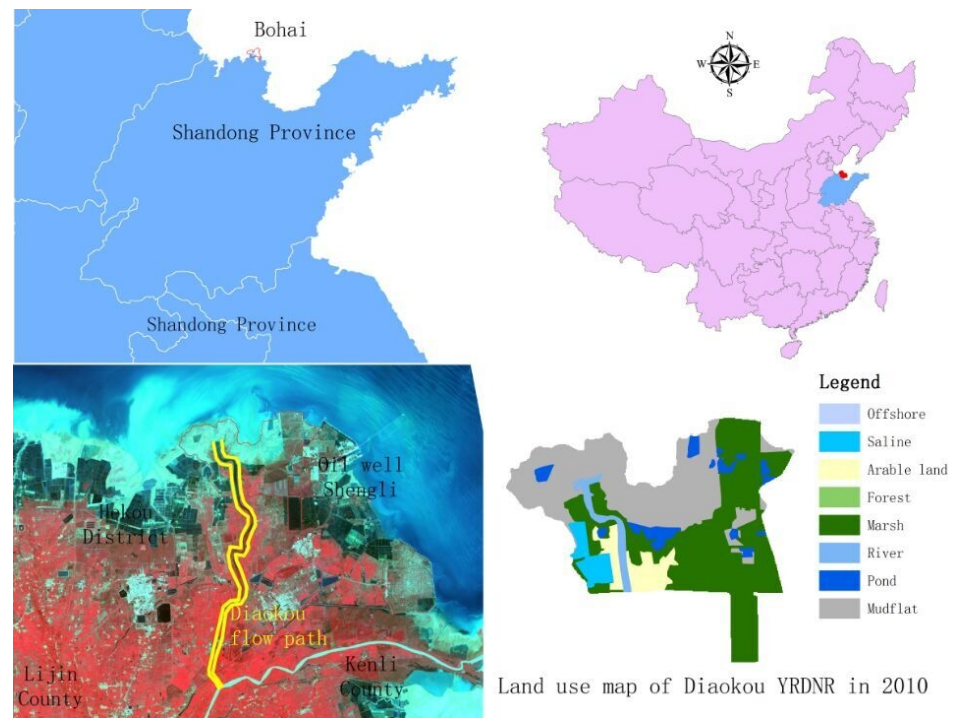

Fig. 1. The location of study area of Diaokouhe

Fig.1. The location of study area of Yellow River Delta Natural Reserve (YRDNR) in Shandong province, China. The YRDNR is located in the coastal areas of Bohai Sea. The restoration Diaokou flow path is on the south bank of the YR. The Yellow line is the boundary of Diaokou flow path.

In 1992, the State Planning Commission has approved the report of "YR flow path plan" organized by YRDWRC and determine that Diaokou flow path as the reserved flow path. The runoff of YR has changed dramatically since 1980s through 1997. The Lijin hydrological station the mean runoff (1950-2010) is $306 \times 10^{8} \mathrm{~m}^{3}$. In 1999, the YR Hydrological Commission started to integrate regulation and the drying up is scare (Fig. 2). Since 2002, the committee started to sand and water regulation (Cui et al., 2009). Owing the continuous flow of YR, especially in 2008, 2009, YR water and sand regulation to conduct ecological transfer water, and the 100,000 ha located in the Qingshuigou flow path has been replenished. About 23,333 ha degraded wetland has been restored and wetland water surface increased from 15\% to 60\% currently. The current Qingshuigou flow path of two side bank has restored wetland about 16,666 ha. In 2009, the YR Conservancy Commission has proposed the strategy 'Reusing Diaokou Reserved flow path and implement the ecological transfer water' and make the two flow path use alternative. Therefore, the YR water resource commission decided to transfer freshwater to Diaokou flow path aiming to restore and protect wetland ecosystem in June 2010 of the flood season during the $10^{\text {th }}$ flow-sediment regulation regime.

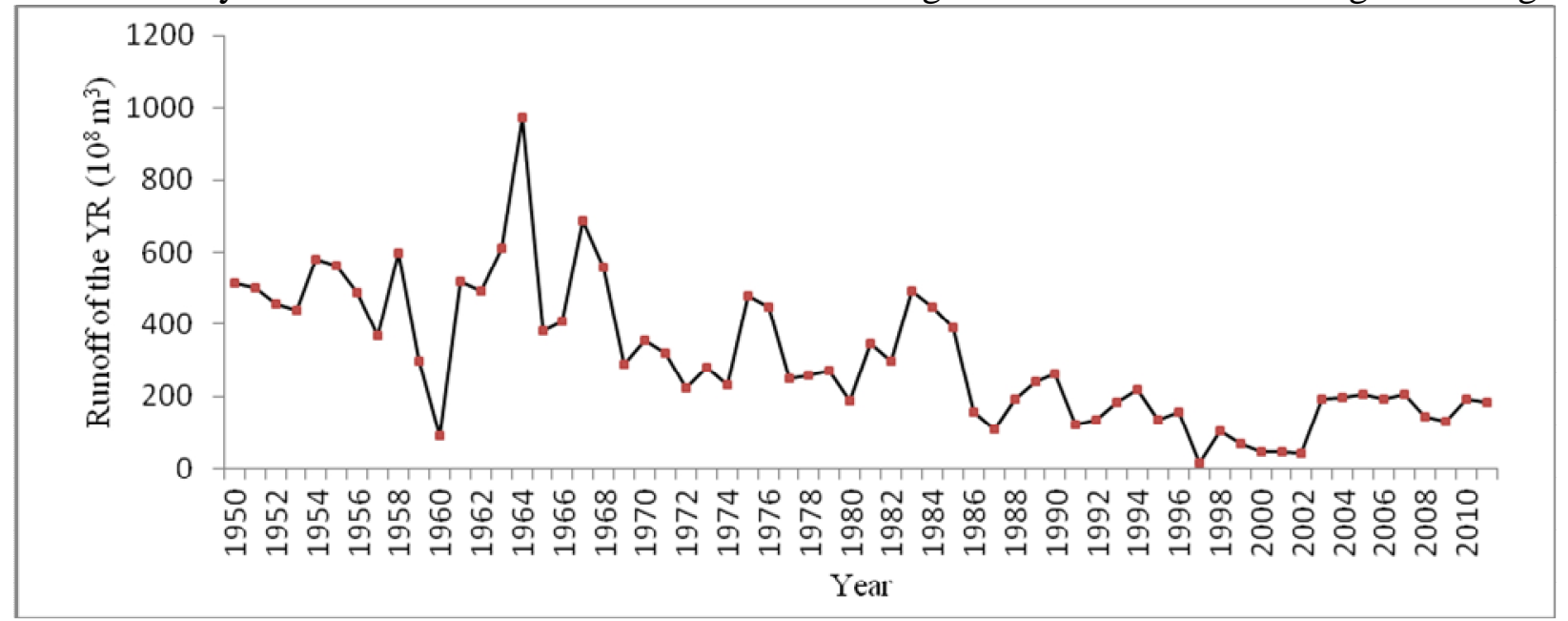

Fig. 2. The runoff of YR

Fig.2. Annual runoff of the YR from 1950 to 2011 (Lijin hydrological station). The runoff of the Yellow River decreased fast from 1984 to 2002 and has caused the Diaokou Natural Reserve wetland 
deterioration. The Diaiokou flow path restoration project was launched in 2010 and the wetland areas and runoff in Diakou flow path has increased fast.

The original Diaokou River flow path has no water flowing to the ocean and has ceased to feed the river for nearly 37 years. For the abandoned estuary wetland, the ecological condition has continued to degrade as a result of global climate change, intensive anthropogenic disturbance, large-scale agricultural development and industrial expansion. Along with the rapid development of YRD, the land exploration, oil exploration, urban development and sea tide intrusion and sea water encroachment, the freshwater wetland area and riverbed of the Diaokou has been shrinking.

(1) Due to the abundance of land, oil, and gas resources, the local government and Shengli Oilfield management bureaus have paid considerable attention to regional economic development. Since 1976, the water has ceased to flow, the embankment has been abandoned, and the profile of the Diaokou channel is faint. The Jinan Military Zone YRD production base and Lijin, Hekou County have conducted land and forestry development. Local government has constructed several high expressways, the harbour, and Dongying Industrial Park adjacent to the coastal areas occupying 90 $\mathrm{km}^{2}$ of riverbed (Wang et al., 2014).

(2) During the past 34 years, because of freshwater supply to the wetland, the ratio of evaporation to precipitation is 3.6:1, and soil salinity is increasing. The average salinity degree is $10.62 \mathrm{~g} / \mathrm{kg}$ in YRD wetland soil. Owing to a lack of fresh water and sand supply in the YR, seawater erosion, and human exploration activities, the feature and terrain and physical feature of river channel has changed, and the coastal line retreated substantially, which poses serious threats to the oilfield infrastructure and oil exploration safety (Luo et al., 2015). Therefore, dredging and removing the flow barriers in the Diaokou river channel and restoring and sustaining the ability of the Diaokou river channel to transfer water and sand during the YR water and sand regulation period can change the estuarine coastal line retreat status fundamentally and protect coastal oilfield production safety. It can also improve water resource utilisation, strengthen the estuarine governance, and provide scientific support for implementing the YR river channel arrangement.

\section{The freshwater transfer to degraded wetland}

The Shandong YR Survey and Design Institute compiled the 'Implement scheme of Diaokou flow path transfer freshwater'. During the sediment flow regulation periods in 2010, 2011, 2012, and 2013, transferring water of the Diaokou River continued for four years and reduced the ecological degradation trend. The restored wetlands were then connected with the river by the channel, thus establishing a hydrological relationship between the river and the project area. The objectives of the Diaokou flow path project were to (i) explore the Diaokou flow path and Qingshuigou flow path alternative utilization and enlarge the flow path utilisation period, and restore the Diaokou ecosystem and (ii) preserve the high levels of biodiversity and typical natural landscapes, establish an education base for the public for degraded ecosystems, and increase public awareness and participation in ecosystem restoration. The restoration process of the abandoned YRD estuarine wetlands included background data collection, the establishment of restoration goals, the design of an implementation scheme, engineering construction, effects monitoring, management, and public participation (Fig. 3).

(1) The first step is to design the implementation scheme, including river path dredging, bridge and hydrological facility construction, removal of the abandoned dam and construction of the method for water transfer. To implement the project, the Shandong YR management Bureau, Dongying municipal government, Shengli Oilfield management Bureau, Jinan Military Zone YRD production base, and the management bureaus of the YRD natural reserve formed the lead group of "Diaokou flow path ecological transfer freshwater coordination leading group," responsible for crucial policy, schemes, responsibilities, organizational structure, water quantity regulation fundraisers, basic information collection, and field surveys. In Aug 5, 2009, the first conference of the water transfer coordinated leading group was held in Dongying, and the Shandong YR management bureau and Dongying local government decided to raise the initial funds to launch the field survey and project. In April, 2010, the YRWRC and Shandong province held the "YRD ecological water transfer symposium" and established the water transfer targets and quantities. The Dongying municipal 
government and YR estuary management bureaus are responsible for land and house demolition, coordination, fund regulation, project implementation, and construction management. The transportation system of the partnership was constructed in 2010 to transfer the YR water to the Diaokou flow path.

(2) The area of transferred freshwater is $0.3667 \times 10^{4} \mathrm{hm}^{2}$, which includes the river path of $0.2333 \times 10^{4} \mathrm{hm}^{2}$ and experiment area of $0.1333 \times 10^{4} \mathrm{hm}^{2}$. Based on the YRD ecological freshwater transferring target, the Diaokou flow path transfer amount reached $3500 \times 10^{4} \mathrm{~m}^{3}$ and transported $20.816 \times 10^{4} \mathrm{t}$ of sand in 2010 , conducted during the period of YR water and sand regulation. The water transfer replenishment areas in the Diaokou area was $0.1347 \times 104 \mathrm{hm} 2$ on Aug 10, 2010. On June 19, 2010, the YR water and sand regulation project began, and the flow rate at the Lijin hydrological station reached $2330 \mathrm{~m}^{3} / \mathrm{s}$. The Cuijia regulation lock experienced flow water for 16 days and a water transfer amount of $2280 \times 10^{4} \mathrm{~m}^{3}$, and sand transfer amount of $11.23 \times 10^{4} \mathrm{t}$. Meanwhile the Cuijia transfer started to operate on July 17, 2010 and ended on Aug 5, 2010 operating for 20 days (Fig. 3, with an average flow rate of $7.76 \mathrm{~m}^{3} / \mathrm{s}$, water transfer amount of $1340 \times 10^{4} \mathrm{~m}^{3}$, sand transfer amount of $9.58 \times 10^{4} \mathrm{t}$. The total project water transfer amount was $3620 \times 10^{4} \mathrm{~m}^{3}$, and the total sand transfer amount was $20.81 \times 10^{4} \mathrm{t}$.

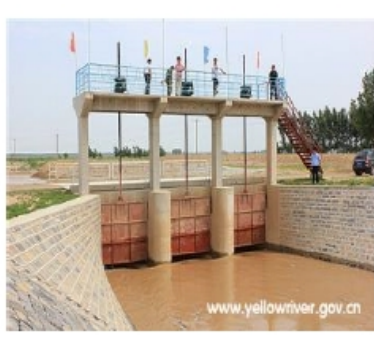

(a)

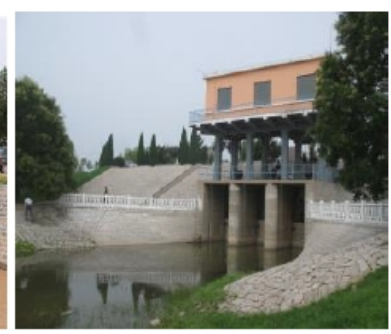

(b)

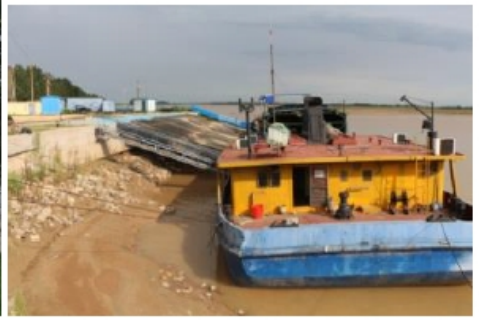

(c)

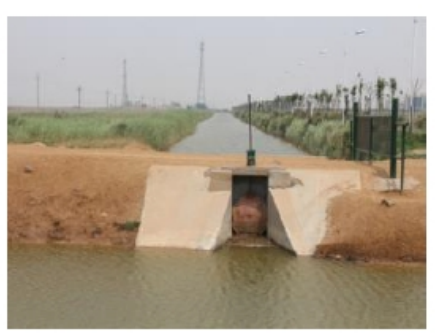

(d)

Fig. 3The transferring freshwater to a banded facility in YRD in 2010

Fig. 3 The transferring freshwater to a banded facility in YRD in 2010. During the restoration process, the local government has constructed many hydrological facilities in the Diaokou b flow path (a)Cui dam, (b)Transport water bridge and dam, (c) Transferring water ship, (d) The dam in YRDNR.

\section{Results}

The freshwater transfer of the Diaokou flow path to abandoned estuarine wetland in 2010 has obtained the obvious ecological effects (Cui et al., 2009).

\section{Increased areas of freshwater wetlands and increased groundwater levels}

The water transfer project has increased the freshwater wetland areas. The remote sensing images in 1992 and 2010 demonstrate that the wetland areas with water have increased from $15 \%$ to $60 \%$, and the Diaokou flow path restoration has increased the water surface area by $526 \mathrm{hm}^{2}$. It has suppressed the development of groundwater saltwater intrusion in the degraded Diaokou wetland. The groundwater level in the tail reaches of the Diaokou along the bank at $1100 \mathrm{~m}$ has risen, increasing by $20 \mathrm{~cm}$ in 2010, the water level clearly rising $550 \mathrm{~m}$ along the bank, the highest amplitude of elevated water level is $65 \mathrm{~cm}$.

The degree of soil salinity in different vegetation communities has been decreasing, especially in the top $0-0.3 \mathrm{~m}$ of soil. The salt content in the top $0.1 \mathrm{~m}$ of soil decreased by $55 \%$ and decreased $41 \%$ in the top $0.3 \mathrm{~m}$, which creates a suitable base for the growth of freshwater wetland aquatic vegetation. These two changes have affected the soil matrix and the ecological succession of driving forces, which is demonstrated by ecotypes and landscape structure (Table 2). The water content in the surface layers at $20 \mathrm{~cm}, 40 \mathrm{~cm}$, and $70 \mathrm{~cm}$ has increased. The main ecosystems of salinization of bare land at low elevations and of halophyte vegetation communities have been replaced by large areas of water and Phragmites marsh (Fig. 6,7). Annual and perennial vegetation that grows at low salt content will evolve into a Phragmites marsh type and in the higher elevations the Tamarix Chinensis 
has the tendency to evolve into Phragmites as well. The beautiful landscape in YRD has been appointed "the most beautiful wetland in China" and is one of the National 4A Level Scenic Spots.

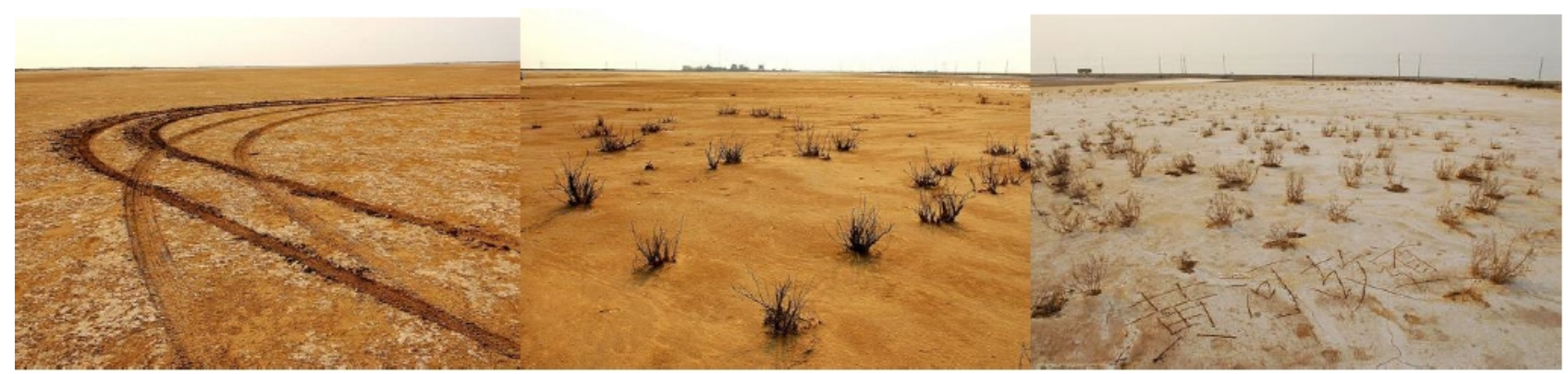

Fig.4 The Diaokou river channel before

Fig.4 The landscape of Diaokou river channel before the transfer project in 2008. Between 1976 and 2010, the Diaokou flow path has no freshwater and has caused the river ecosystem degraded continued(source: http://www.sdhh.gov.cn/ztgz/stds/07/10009.shtml).

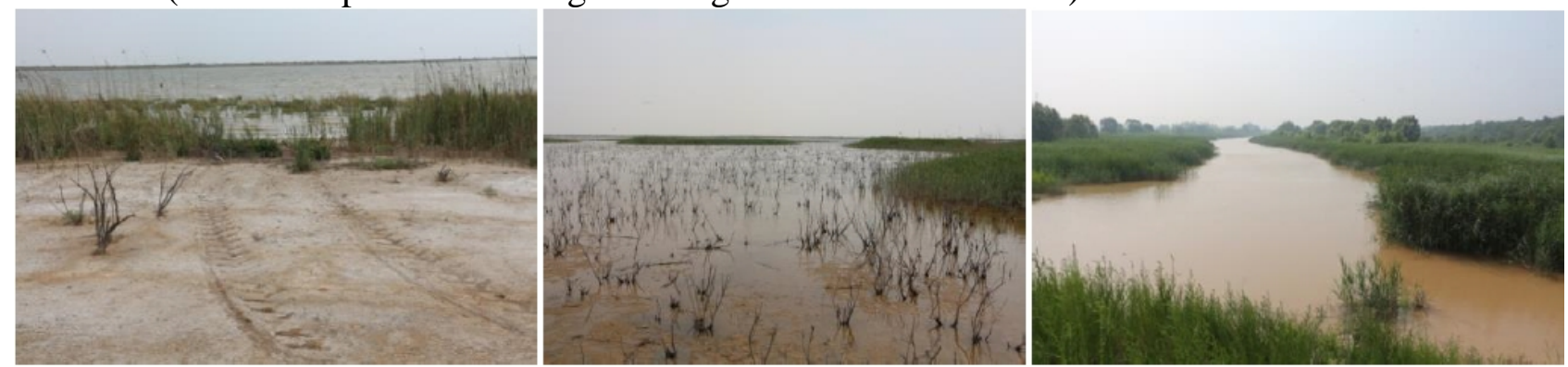

Fig.5 The Diaokou river channel after

Fig.5 The landscape of Diaokou river channel after the transferring water in 2014. The wetland ecosystem has been restored with increased water surface areas and biodiversity.

\section{Bird diversity change}

The large protected bird habitat has been restored, and the number of waterfowl has increased substantially. In 2000, there were 283 species of birds and nine types of national Class 1 key protected birds and 41 types of Class 2 birds, with a total number of 4 million birds. Now, there are 367 species of birds, 12 types of national Class 1 key protected birds, and 51 types of Class 2 protected birds, with a total number of 6 million birds. Comparing the summer of 2009 with the summer of 2010, the number of waterfowl in the Diaokou tail that reach wetland restoration areas increased by 5000 . The endangered species of red-crowned crane increased by 11 in 2010 and by 19 in 2011 and the oriental white stork has increased by 18 , suggesting the improved effect of Diaokou wetland ecological water transfer. There were no oriental white storks sensitive to wetland environmental change before 2002 in the YRD, only one pair in 2003 and 36 in 2013. Now the YRD has become the most important oriental white stork breeding place in the world and Dongying was named China's hometown of the oriental white stork by the Chinese Wild Animal Protection Association. Furthermore, the number of aquatic birds has increased to 4700 in 2010 and 12,000 in 2011 (Fig. 8). The total number of waterfowl was 9,020 in $2009,13,803$ in 2010, and 23,782 in 2011. The number of the four waterfowl was 3,700 in $2009,8,350$ in 2010 , and 17,370 in 2011. Meanwhile, the number of waterfowl in saltwater has decreased, and the number was 2,996, 2,913, and 1,459 in the three years. 


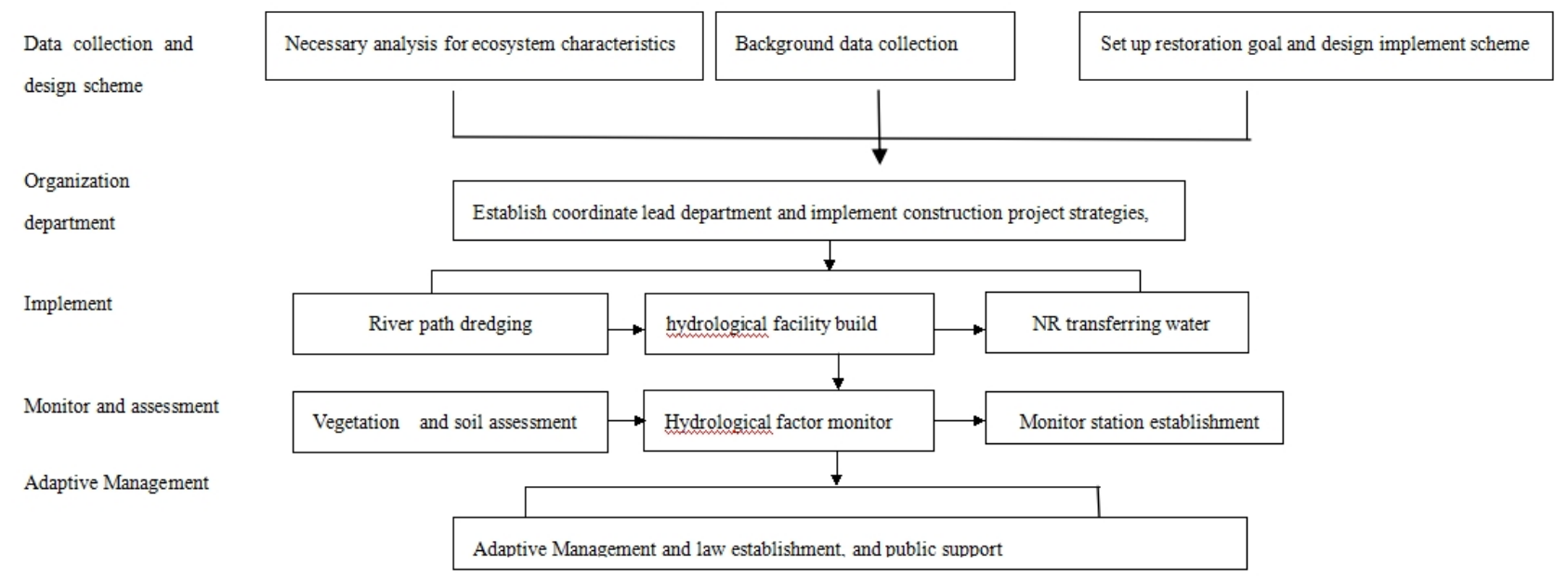

Fig.6 Outline of restoration process

Fig.6 Outline of restoration process of the Diaokou flow path. The restoration process of abandoned YRD estuarine wetland included background data collection, set up the restoration goals, design the implement scheme, and engineering construction, effect monitoring, management and public participation.

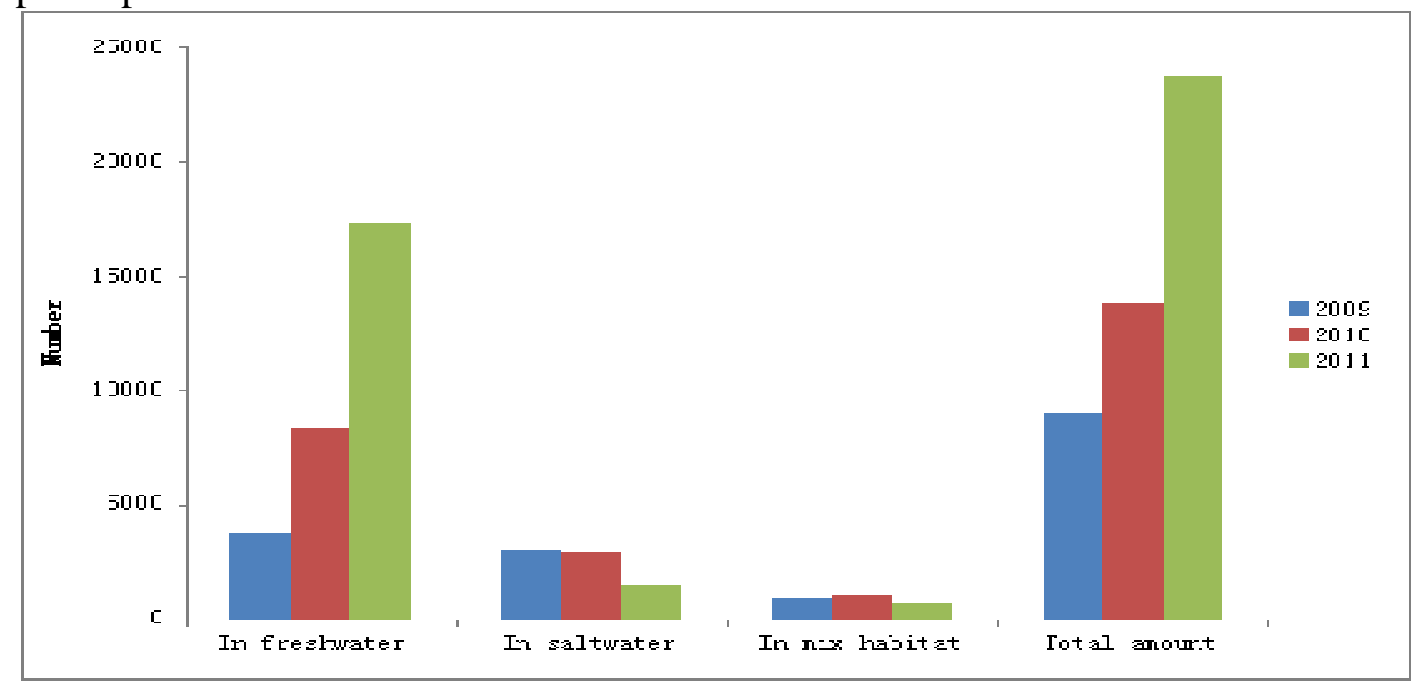

Fig.7. The number change of waterfowl

Fig.7. The number changes of waterfowl in freshwater, saltwater, mix habitat in 2009, 2010, 2011. The number of waterflowl has increased fast since 2010 .

\section{Discussion}

Transferring freshwater into abandoned wetlands in the YRD has provided useful experiences and lessons, which may be helpful for planners in implementing restoration projects in other parts of China, managers and decision makers. The assessment of the water transfer effect included the water areas, water salinity change, vegetation change, land use change, and bird diversity. All of these parameters were clear and measurable (Cui et al., 2009).

\section{Achievements gained during the restoration project}

(1) To ensure Diaokou water ecosystem safety, it is essential to estimate the watershed's ecological water demand.

The estuarine ecological water demand is the quantity of water needed to sustain estuarine salt-freshwater balance. The engineering project should be analysed scientifically to determine the reasonable amount of water transfer. Consideration of riverbed impoundment and evaporation 
permeate should help determine the reasonable water transfer quantity, especially for the transfer condition and ecological ecosystem change during the YR sand and water regulation period. Therefore, it is necessary to guarantee the transportation of riverbed sand to maintain the ocean's dynamic balance and safety (Li et al., 2015; Luo 2015; Borsje et al., 2011).

(2) The restoration scheme involves many departments and resource management mitigation

Estuarine management involves many governmental departments, such as the YR estuarine department, Shengli Oilfield, ocean bureaus, and natural reserve management bureaus. These departments adopt different management rules and policies and have different management targets and therefore may conflict with each other. The multi-department management has had negative effects upon comprehensive treatment and exploration of estuarine areas. A coordinated mechanism needs to be established to plan flow path resource development and estuarine governance. Because the water and sediment of the YR watershed is controlled by YRWRC, it is necessary that the estuarine management mechanism is led by YRWRC and the local government, Shengli Oilfield, ocean bureaus, environmental protection bureaus. The YR Water Resources Commission is responsible for water quantity dispatch. The YR Water Resources Commission Hydrology Bureaus are responsible for the observation of water discharge, sand content, water quantity, quantity of runoff to the sea and for monitoring the quantity of water that flows into the natural reserve. The YR Watershed Water Resource Protection Bureau is responsible for ecosystem observation. The Shandong YR Bureau will help YRWRC to regulate water quantity and to guide the water transfer in the field. The Dongying municipal government is responsible for field management and coordination, water quantity regulation into the natural reserve and the YR Estuarine Management Bureau is responsible for dam construction and management, regulation, typical water profile observation, directing the compilation of emergency action plans and techniques. The Jinan Military Zone YRD production base, Agricultural Bureau, Lijin and Hekou governments, and the YRDNR Management Bureau are responsible for engineering and flow path safety.

In 2011, the YR Estuary Management Bureaus held a conference of water and sand regulations and initiated an operation mechanism of water and sand regulations, establishing the comprehensive dispatch group, water status, inspection group, and ecological condition dispatch. During this period, the YRWRC and Shandong YR Bureau dispatch groups were on site working, supervising, coordinating, inspecting, and guiding the transfer of water and improving the ecological water transfer and Diaokou and provide organization guarantee for completing the ecological transferring water. During the restoration effort all stakeholders including governments and academic institutions, were involved in planning, implementation, performance assessment, and management..

Coastal resources require the resolution of local resource use conflicts (Stepanova, 2015). Conflict resolution is part of the process of transforming conflicts into cooperation- through dialogue, reconciliation, negotiation and the participation of stakeholders in conflict with their interests, needs and values taken into account. Concepts and frameworks for conflict resolution include dialogue, participation, collaboration, conflict transformation, negotiation, capacity building, bridging organizations, and adaptive management, among others. Resolution is often addressed through Integrated Coastal Zone Management (ICZM) as a framework strategy that implies stakeholder participation, consultation, and negotiation (Tuda et al., 2014; Paterson et al., 2010).

(3) A monitoring program was developed, and adaptive management was applied during the entire restoration process

Monitoring the dynamics of the wetland restoration process can provide basic information for wetland restoration effect assessment (Huang et al., 2012). A monitoring program was developed, and parameters included hydrology, biological factors, water and landscape, vegetation types, soil water content, soil salinity, bird status, land use change, and environmental baseline information. In the long term, after complicated system and base work, the YR estuarine delta ecological regulation effect assessment started in 2010 and is important work for YRWRC. The YR Water Resources Protection Institute has evaluated the effects for seven years and has increased the water environment monitoring point to conduct system investigation that includes the collection of 90 soil samples, 40 vegetation samples, and 30 surface water samples for the wetland restoration areas. However, owing 
to the short monitoring period, it is difficult to monitor wetland vegetation succession. The assessment of ecological water transfer in YRD is a long, complicated process. Systematic, detailed and comprehensive observation data are the base for launching a YRD estuarine ecological water transfer effect assessment. The YR water and sand regulation project often faces difficulty because of current and historical ecological system data support in the estuarine areas. However, the ecological monitoring base is very weak, and an estuarine ecological monitoring station and network, monitoring system, and effective long-term mechanism have not been established. Thus, it is urgent to establish a long-term YRD estuarine area ecological effect monitoring system and effect assessment mechanism to conduct long-term tracking and monitoring, investigation, and analysis (Craft, 2007). Therefore, the long-term system monitoring and research mechanism of water resources, ecological succession response relationship, and long-term monitoring must be surveyed to evaluate transfer effects in sensitive habitats and the ecological changes over time for the Diaokou flow path before and after the water transfer.

The YRWRC should explore the YRD estuarine water ecosystem monitoring and assessment system and conduct YR water and sediment regulation and ecological regulation tracking assessment, provide system support for YR water quantity comprehensive regulation and estuarine comprehensive treatment and development. Along with increasing the size of the Diaokou flow path ecological water transfer, to comprehend the effects of the Diaokou riverbed water transfer and to analyse these effects (including scouring and silting) on the Diaokou riverbed estuarine areas, it will be necessary to gradually and systematically enlarge the boundaries of ecological monitoring.

It is recommended to apply RS and GIS to create an evolution model of underground water and to evaluate the ecology of the landscape, to monitor and model the underground water flow field and the composition of wetland ecosystems, identifying sensitive birds for protection, the disturbances and driving forces of the regional ecosystem and key ecological units that balance the succession. We suggest strengthening observations of hydrological factors, such as changes in estuarine vegetation, water quality, and environmental changes underground and above ground. However, research on a broader array of wetland issues is required to evaluate freshwater treatment effects especially with respect to SOC responses to changes in hydrological regimes (Koh et al., 2014; Wang et al., 2014). The construction of an underground water monitoring network for assessing underwater level, $\mathrm{pH}$ value, and salinity can reflect and evaluate the water transferring effect for improving wetland ecosystems. The establishment of a water quantity and quality monitoring management system will help strengthen the monitoring of the Diaokou flow path evolution, hydrological factors, sediment, and marine dynamics and help explore related legal issues. The addition of fresh water and the concomitant increase in soil moisture content enhances the accumulation of SOC in the YRD (Wang et al., 2011). It is needed to strengthen the impact of water transfer upon the current flow path of Qingshuigou. We should study the relationship among various physical and chemical properties in the soil that change after freshwater treatment.

Environmental Impact Assessment (EIA) aims at integrating environmental considerations in the decision-making system, avoiding or minimizing adverse impacts, protecting natural systems and their ecological processes, and implementing principles of sustainable developments (Naser, 2015). Recognizing the role of EIA in protecting environments from degradation and pollution associated with coastal development, studies should investigate the effectiveness of EIA in protecting coastal and marine environments (Valentini et al., 2015).

\section{(4) Public education programs have done well and should be strengthened}

Public education programs have also been strengthened since 2003, and the YRD was selected as the demonstration site for education in wetland science in 2000. The YRDNR are also commonly used as the education centres for students and the public, just as in Dongying. The Diaokou wetland restoration project was chosen as a demonstration site for degraded wetlands by the YR Management Commission and Shandong province government, and officials and the public were invited to visit the site several times. The YRD Sustainable Development Forum has been held every year since 2005, and Dongying was selected as one of the cities for Shandong Blue Economic Zone development. Tourists come to the area from all over the world. With the continued growth of the tourism industry 
over the past few decades, the demand for interpretive experiences and education on marine tours has increased as well. Tourism in RYD has included bird watching and wetland education. The local government has taken effective measures to inform the public of the importance of water transfer and should organize discussions with the construction industry as well. According to the "YR Estuarine Management Method", the construction of permanent buildings is prohibited in the riverbed. Unfortunately, there are many unapproved buildings to be reclaimed in the area of the riverbed. Therefore, it is essential to realize the importance of propaganda and education to make the public aware of the plan to restore the flow path of the Diaokou. The government should strengthen the laws and regulations, improve marine spatial planning, fully evaluate the negative impacts of reclamation, and increase awareness of coastal issues and public involvement in reclamation management (Masud et al., 2014).

Stakeholder participation is an important concept in marine environmental management; thus, stakeholder acceptance and opinions might influence policy decision making and effectiveness (Chen et al., 2015; Ruiz-Frau et al., 2015; Puente-Rodríguez et al., 2015). The integration of science-based and stakeholder-based approaches offers the potential to reach balanced solutions that can provide a consensus between conservationists and stakeholders, as it allows for the consideration of stakeholders' interests while still meeting conservation needs. In the marine environment planning decision support tools for the designation of MPAs has facilitated the integration of spatially explicit biological and socioeconomic information. The fundamental principles of coastal management assume that management actions adequately reflect the best available science and fully consider stakeholder perspectives (Ariza et al., 2014). By exploring the different objectives for coastal and marine management, the relationships between stakeholder groups, and the overlap in their interests, we identify barriers and encourage the stakeholders' commitment and cooperation towards more strategic coastal and marine management (Mason et al., 2015). Multiple use conflicts are common in the Diaokou flow path due to competition over natural resources among diverse stakeholders associated with the ecosystem, including local farmers, the Jinan Military Areas Production Base, and the Natural Reserve Management Bureau (Xie et al., 2014). The integration of a stakeholder driven process with a science-based approach can be used to achieve conservation targets while simultaneously accounting for multiple stakeholders' preferences, therefore avoiding potential conflicts between conservationists and stakeholders and among stakeholder groups.

Integrated coastal management (ICM) is widely accepted and is seen as a potent and balanced planning and management process (Celliers et al., 2015; Hassanali, 2015; Ho et al., 2014). Spatial analyses employing geographic information system and modelling techniques have been used for MPA designs (Chen et al., 2015). Optimal solutions generated solely through prioritisation software may be effective from a conservation point of view, but they often lack stakeholder support and are thus challenging to implement.

\section{(5) Implement strict riverbed management and law establishment}

According to the Flood Control Law of China, the Shandong Province YR riverbed management rule, and the YR mouth management regulation, we should erase the management boundary of the YR Diaokou flow path and make a specific rule for Diaokou exploration, clearly demonstrate the management and protection body and raise funds for Diaokou ecosystem protection, construction and Diaokou flow path management. The management methods of the Diaokou flow path of Dongying City should be proposed as soon as possible. To adapt the situation of YR management, it is necessary to establish watershed legislation and based on current water legislation, we should expedite the legislation process of "Watershed Law and YR Law". There are many laws and rules in the field of YR water resource allocation, whereas the laws regarding development in the areas of the YR estuarine mouth are too scarce. We should strengthen management of the flow path, as well as the laws regarding the estuarine area, which currently conflict with the natural resource (NR) management laws ( $\mathrm{Li}$ et al., 2015). We should strengthen YR estuarine evolution law research to more effectively evaluate the YR estuarine flow path status. The local government should implement the strictest riverbed management system and strengthen law enforcement while the government should have a strict administrative examination of river flow construction projects and normal 
inspection of river flow. The weak water administrative enforcement group poses a threat to effective Diaokou flow path management, ecological safety and a reserved flow path. Effective measures must be applied to remove squatter buildings step by step and to prohibit new buildings in the riverbed and as well as cultivation activities.

Ecosystem-based management has heralded broader usage of economic valuation of ecosystem services to balance the multiple benefits provided by ecosystems. Ecosystem-based management (EBM) is promoted as an alternative to traditional approaches for managing natural resources (Cárcamo et al., 2014). These results provide conservation managers with direction to adapt the ICZM protocol and conservation strategies to improve social acceptance and promote effective governance in coastal environments (Ernoul and Wardell-Johnson, 2015). There is enough evidence to suggest that the acceptance, involvement, and early participation of the affected community in planning and decision-making activities are key for effective implementation of marine conservation and management measures (Sherman, 2014; Li et al., 2015). There should be accountable and transparent dialogues and mechanisms for all of the stakeholders and actors to be actively involved in the development of institutions, and evaluating and monitoring governance processes (Ho et al., 2014; Mason et al., 2015). While institutional and governance problems are stated as substantive challenges for effective management, institutional and governance indicators have also been used to demonstrate the management effectiveness of MPAs.

\section{Lessons during the restoration project}

Although the water transfer since 2010 has had positive effects, it has also had negative effects.

(1) Degradation causes, types, process, and degree were addressed but were too descriptive

The reasons for wetland degradation in the YRDNR were described, including oil industry development, global climate change, agricultural development and other anthropogenic activities, and improper management. However, the degree of degradation and suggestions for improved management have never been evaluated. During the management of abandoned wetlands, a clear understanding of the elements of the ecosystem will help the decision makers to propose appropriate scientific restoration activities. The objectives of restoration in the YRD were to re-establish the wetland ecosystem and restore the Diaokou flow path landscape structure and function. However, a successful restoration project of the YRD should not just focus on flowing water but should address the full range of biological diversity and ecological processes of the ecosystem (Xie et al., 2014). Although much of the literature notes the importance of these hydrological factors in the restoration effort of the abandoned estuarine wetland, they were mainly descriptive with no scientific evidence to support the claim.

(2) Adequate background data, such as ecological and socio-economic data should be collected but some important information was scarcely obtained

Background data, such as socio-economic development data, land use, hydrological factors, river elevation, vegetation cover, sediment quality, salinity degree, and plant structure should be collected before project implementation. Applying this information to determine the major reasons for estuarine ecosystem degradation is critical to adopt suitable engineering measures. Through the investigation assessment, the YR water resource has saved detailed estuarine key areas data and formed systematic investigation scheme, and lay a good condition for YR estuarine water ecosystem monitor and assessment system. It is urgent to incorporate ecological data into estuarine restoration projects for the successful wetland restorations. However, we lack significant and crucial information and have restricted the estuarine retreatment improvement during restoration practice until now. For example, there are $112 \mathrm{~km}$ between the Lijin hydrological station and the estuarine area and because the hydrological characteristics of the Lijin station cannot represent the riverbed condition of Diaokou it is difficult to make more scientific analysis for depositing and scouring in the estuarine areas. Thus, it is necessary to establish a hydrological station in the estuarine area to collect and analyse the needed sand and water data. 


\section{(3) Restoration projects should consider the costs and effects, and fund raising methods}

Cost-effective monitoring programs have been developed in restoration projects, including programs that monitor the salinity degree levels, species diversity and endangered bird diversity. The Dongying government and Shengli Oilfield have invested approximately 13.5 million RMB to finance the water transfer operation; however, owing to large costs, this fund is only able to meet the demands of direct operation charges and significant compensation for demolition is needed. Funds should be secured to maintain the restoration effort and ensure that the experiment project operates successfully. The cost of construction and operation of the Diaokou flow course ecological water transfer project is 10.48 million RMB to transport $36.20 \times 106 \mathrm{~m} 3$, with an average cost to water transfer of $0.29 \mathrm{RMB} / \mathrm{m} 3$ to restore a wetland area of $1400 \mathrm{hm} 2$. Meanwhile, the freshwater wetland flow into the sea and Diaokou estuarine coastal water temperature increase and salinity decrease is beneficial to fish growth in the Diaokou flow path. Public funding has also been allocated for research into small scale applications of ecological engineering, as well as for detailed studies of a range of coastal marine organisms (Loke et al., 2014). The YRD water transfer ecological project is a long-term process, and the Diaokou flow restoration project requires a similar process to be able to operate normally. To play the role of experiment engineer and maintain the previous water flow, a special fund should be arranged to fix, maintain, and dredge the river channel, remove debris from the water and ensure the freshwater lift facility to operate.

\section{Conclusion}

The establishment of MPAs is often controversial, as the closure of portions of the sea to human activities can have negative impacts on those sectors of society affected by the closures (Ruiz-Frau et al., 2015; Shen et al., 2015; Lai et al., 2015). The increasing rate of land reclamation has contributed substantially to the deterioration of marine habitats and resources (Naser, 2015). Large-scale dredging and reclamation activities may affect both the integrity and productivity of several coastal and marine ecosystems. In recent years, China has launched a series of programs to restore typical coastal ecosystems, and many successful cases have been achieved (Chen et al., 2012). The restoration of hydrologic links between the YR and the floodplain wetlands is an effective way to re-establish both ecosystem structure and functions (Cui et al., 2009). Cui et al. (2009) found that wetland restoration efforts have increased efficiency in reducing water pollution levels, re-established the vegetation community quickly, and attracted more birds. The YRD High Efficiency Ecological Economic construction depends upon the safety of YR flood control as well as the need for a relatively stable YR flow path.

Since 1990, the effects of climate change and human activities have caused the YR water quantity to decrease while the social and economic demands of for the water have increased, with no comprehensive regulation and management of YR water, causing the YR to dry up. Since 1999, the YRWRC has started comprehensive management and regulation of YR water resources and has used engineering techniques, legal methods, and economic measures to ensure the flow of YR, which has restored the YRD large scale wetland ecosystem and its biodiversity. Since 2010, the YRD ecological water transfer has maintained the ecological demand for water, bird habitat quality has increased, biodiversity in estuarine areas has increased, the ecosystem has been restored, and received obvious social and economic benefits. These results confirmed the necessity to re-establish the hydrological conditions and provided useful experiences for other wetland restoration projects in estuary areas. Detailed investigation of these components of a target ecosystem and how they change during ecosystem development is required. Long-term monitoring is essential to evaluate the effects of wetland restoration projects (Cui et al., 2009; Elliott et al., 2007). However, there are still many weaknesses which may create barriers in the efficiency and success of marine ecosystem restoration efforts in China. We need to make adaptive management and results dissemination into one routine mechanism in our future marine ecosystem restoration processes in China. The ecological restoration of wetlands requires a continuous freshwater supplement to consolidate the effects of water transfer. Successfully restoring a diversity of wetlands, which are functionally equivalent to their natural counterparts, requires a more complex approach than simply adding water. An ecosystem restoration 
assessment (ERA) should include restoration objectives and changes in the landscape adjacent to protected areas. Further studies are needed to determine long-term changes in soil processes and the plant communities within the wetlands in the YRD, and especially to document long-term and large scale changes in this system. YRD's endeavours and solutions to finding a balance between ecosystem conservation and industry development can help inform marine sustainability planning in other coastal cities facing similar challenges.

\section{Acknowledgments}

This research is supported by the National Natural Science Foundation of China (No. 41361018,41101084), opening fund (PK2013003) of Key Laboratory of Poyang Lake Wetland and Watershed Research (Jiangxi Normal University), Ministry of Education. National Basic Research Program of China (2010CB950900; 2009CB421100), the Collaborative Innovation Center for Major Ecological Security Issues of Jiangxi Province and Monitoring Implementation (No. JXS-EW-00), the open fund of Jiangsu key laboratory of environmental change \& ecological construction. We would like to express our gratitude to two anonymous reviewers for their useful comments for previous version.

\section{References}

1. Aldous, A., McCormick, P., Ferguson, C., Graham, S., Craft, C., 2005. Hydrologic regime controls soil phosphorus fluxes in restoration and undisturbed wetlands. Restor. Ecol. 2, 341-347.

2. Ariza, E., Lindeman, K.C., Mozumder, P., Suman, D.O., 2014. Beach management in Florida: Assessing stakeholder perceptions on governance. Ocean Coast. Manag. 96, 82-93.

3. Bermas-Atrigenio, N.A., Chua, T.E., 2013. Utilizing science in advancing marine ecosystem-based management. Ocean Coast. Manag. 81, 1-6.

4. Borsje, B.W., van Wesenbeeck B.K., Dekker, F., Paalvast, P., Bouma, T.J., van Katwijk, M.M., de Vries, M.B., 2011. How ecological engineering can serve in coastal protection. Ecol. Eng. 37, 113-122.

5. Cárcamo, P.F., Garay-Flühmann, R., Gaymer, C.F., 2014. Collaboration and knowledge networks in coastal resources management: how critical stakeholders interact for multiple-use marine protected areas implementation. Ocean Coast. Manag. 91, 5-16.

6. Celliers, L., Colenbrander, D.R., Breetzke, T., Oelofse, G., 2015. Towards increased degrees of integrated coastal management in the City of Cape Town, South Africa. Ocean Coast. Manag. 105, 138-153.

7. Chen, Y.L., Liu, H.H., Chuang, C.T., Lu, H.J., 2015. The factors affecting stakeholders' acceptance of offshore wind farms along the western coast of Taiwan: Evidence from stakeholders' perceptions. Ocean Coast. Manag. 109, 40-50.

8. Chen, B., Yu, W.W., Liu, W.H., Liu, Z.H., 2012. An assessment on restoration of typical marine ecosystems in China-Achievements and lessons. Ocean Coast. Manag. 57, 53-61.

9. Craft, C., 2007. Freshwater input structures soil properties, vertical accretion and nutrient accumulation of Georgia and United States tidal marshes. Limnol. Oceanogr. 52, 1220-1230.

10. Cui, B.S., Yang, Q.C., Yang, Z.F., Zhang, K.J., 2009. Evaluating the ecological performance of wetland restoration in the Yellow River Delta, China. Ecol. Eng. 35, 1090-1103.

11. Day, J., Hunter, R., Keim, R.F., DeLaune, R., Shaffer, G., Evers, E., Reed, D., Brantley, C., Kemp, P., Day, J., Hunter, M., 2012. Ecological response of forested wetlands with and without large-scale Mississippi River input: implications for management. Ecol. Eng. 46, 57-67.

12. Elliott, M., Burdon, D., Hemingway, K.L., Apitz, S.E., 2007. Estuarine, coastal and marine ecosystem restoration: confusing management and science-a revision of concepts. Estuarine, Coast Shelf S. 74, 349-366. 
13. Ernoul, L., Wardell-Johnson, A., 2015. Environmental discourses: Understanding the implications on ICZM protocol implementation in two Mediterranean deltas. Ocean Coast. Manag. 103, 97-108.

14. Ho, T.V.T., Woodley, S., Cottrell, A., Valentine, P., 2014. A multilevel analytical framework for more-effective governance in human-natural systems: A case study of marine protected areas in Vietnam. Ocean Coast. Manag. 90, 11-19.

15. Huang, C., Liu, G.H., Fu, X., Li, Y.F., Liu, Q.S., Wang, X.G., 2012. Monitoring and evaluation of wetland restoration in the abandoned Diaokou estuary of Yellow River Delta based on HJ-1 remote sensing data. Prog. Phys. Geog. 31, 570-576 (in Chinese).

16. Hassanali, K., 2015. Improving ocean and coastal governance in Trinidad and Tobago-Moving towards ICZM. Ocean Coast. Manag. 106, 1-9.

17. Hu, W.P., Zhai, S.J., Zhu, Z.C., Han, H.J., 2008. Impacts of the Yangtze River water transfer on the restoration of Lake Taihu. Ecol. Eng. 34, 30-49.

18. Jones, K., Hanna, E., 2004. Design and implementation of an ecological engineering approach to coastal restoration at Loyola Beach, Kleberg County, Texas. Ecol. Eng. 22, 249-261.

19. Koh, C.H., de Jonge, V.N., 2014. Stopping the disastrous embankments of coastal wetlands by implementing effective management principles: Yellow Sea and Korea compared to the European Wadden Sea. Ocean Coast. Manag. 102, 604-621.

20. Kristensen, E.A., Kronvang, B., Wibery-Larsen, P., Thodsen, H., Nielsen, C., Amor, E., Friberg, N., Pedersen, M.L., Baattrup-Pedersen, A., 2014. 10 years after the largest river restoration project in Northern Europe: hydromorphological changes on multiple scales in River Skjern. Ecol. Eng. 66, 141-149.

21. Lai, S., Loke, L.H.L., Hilton, M.J., Bouma, T.J., Todd, P.A., 2015. The effects of urbanisation on coastal habitats and the potential for ecological engineering: A Singapore case study. Ocean Coast. Manag. 103, 78-85.

22. Leeds, J.A., Garrett, P.B., Newman, J.M., 2009. Assessing impact of hydro-pattern restoration of an overdrained wetland on soil nutrients, vegetation and fire. Restor. Ecol. 17, 460-469.

23. Li, X., Zhao, Y., Shi, C.L., Sha, J., Wang, Z.L., Wang, Y.Q., 2015. Application of water evaluation and planning (WEAP) model for water resources management strategy estimation in coastal Binhai New Area, China. Ocean Coast. Manag. 106,97-109.

24. Li, R.Q., Li, Y.F., van den, Brink, M., Woltjer, J., 2015. The capacities of institutions for the integration of ecosystem services in coastal strategic planning: the case of Jiaozhou Bay. Ocean Coast. Manag. 107, 1-15.

25. Li, S.N., Wang, G.X., Deng, W., Hu, Y.M., Hu, W.W., 2009. Influence of hydrology process on wetland landscape pattern: a case study in the Yellow River Delta. Ecol. Eng. 35, 1719-1726.

26. Loke, L.H.L., Jachowski, N.R., Bouma, T.J., Ladle, R. J., Todd, P.A., 2014. Complexity for artificial substrates (CASU): software for creating and visualizing habitat complexity. Plos ONE. 9, e87990.

27. Luo, S.L., Cai, F., Liu, H.J., Lei, G., Qi, H.S., Su, X.Z., 2015. Adaptive measures adopted for risk reduction of coastal erosion in the People's Republic of China. Ocean Coast. Manag. 103, 134-145.

28. Mason, C.M., Lim-Camacho, L., Scheepers, K., Parr, J.M., 2015. Testing the water: understanding stakeholder readiness for strategic coastal and marine management. Ocean Coast. Manag. 104, 45-56.

29. Masud, M.M., Kari, F.B., Yahaya, S.R.B., Al-Amin, A.Q., 2014. Impact of residents' livelihoods on attitudes towards environmental conservation behavior: An empirical investigation of Tioman Island Marine Park areas, Malaysia. Ocean Coast. Manag. 93, 7-14.

30. Mitsch, W.J., Day, J.W., 2006. Restoration of wetlands in the Mississippi-Ohio-Missouri (MOM) River Basin: experience and needed research. Ecol. Eng. 26, 55-69.

31. Morandi, B., Piégay, H., Lamouroux, N., Vaudor, L., 2014. How is success or failure in river restoration projects evaluated? Feedback from French restoration projects. J. Environ. Manage. 137, 178-188. 
32. Naser, H.A., 2015. The role of environmental impact assessment in protecting coastal and marine environments in rapidly developing islands: the case of Bahrain, Arabian Gulf. Ocean Coast. Manag. 104, 159-169.

33. Paterson, B., Isaacs, M., Hara, M., Jarre, A., Moloney, C.L., 2010. Transdisciplinary cooperation for an ecosystem approach to fisheries: A case study from the South African sardine fishery. Mar. Policy. 34, 782-794.

34. Paalvast, P., van der, Velde, G., 2014. Long term anthropogenic changes and ecosystem service consequences in the northern part of the complex Rhine-Meuse estuarine system. Ocean Coast. Manag. 92, 50-64.

35. Puente-Rodríguez, D., Giebels, D., de Jonge, V.N., 2014. Strengthening coastal zone management in the Wadden Sea by applying 'knowledge-practice interfaces'. Ocean Coast. Manag. 108, 27-38.

36. Qiu, W.F., Wang, B., Jones, P.J.S., Axmacher, J.C., 2009. Challenges in developing China's marine protected area system. Mar. Policy. 33, 599-605.

37. Ruiz-Frau, A., Possingham, H.P., Edwards-Jones, G., Klein, C.J., Segan, D., Kaiser, M.J., 2015. A multidisciplinary approach in the design of marine protected areas: Integration of science and stakeholder based methods. Ocean Coast. Manag. 103, 86-93.

38. Sherman, K., 2014. Adaptive management institutions at the regional level: The case of Large Marine Ecosystems. Ocean Coast. Manag. 90, 38-49.

39. Stepanova, O., 2015. Conflict resolution in coastal resource management: comparative analysis of case studies from four European countries. Ocean Coast. Manag. 103, 109-122.

40. Theriot, J.M., Conkle, J.L., Pezeshki, S.R., DeLaune, R.D., White, J.R., 2013. Will hydrologic restoration of Mississippi River riparian wetlands improve their critical biogeochemical functions? Ecol. Eng. 60, 192-198.

41. Tuda, A.O., Stevens, T.F., Rodwell, L.D., 2014. Resolving coastal conflicts using marine spatial planning. J. Environ. Manag. 133, 59-68.

42. Valentini, E., Taramelli, A., Filipponi, F., Guilio, S., 2015. An effective procedure for EUNIS and Natura 2000 habitat type mapping in estuarine ecosystems integrating ecological knowledge and remote sensing analysis. Ocean Coast. Manag. 108, 52-64.

43. Wang, W., Liu, H., Li, Y.Q., Su, J.L., 2014. Development and management of land reclamation in China. Ocean Coast. Manag. 102, 415-425.

44. Wang, H., Wang, R.Q., Yu, Y., Mitchell, M.J., Zhang, L.J., 2011. Soil organic carbon of degraded wetlands treats with freshwater in the Yellow River Delta, China. J. Environ. Manage. 92, 2628-2633.

45. Xie, Z.L., Xu, L.F., Liu, J.Y., Duan, X.F., Xu, X.G., 2012. Analysis of boundary adjustments and land use policy changes - A case study of Tianjin Palaecocoast and wetland national natural reserve, China. Ocean Coast. Manag. 56, 56-63.

46. Xie, Z.L., Sun, Z.G., Zhang, H., Zhai J., 2014. Contamination assessment of arsenic and heavy metals in a typical abandoned estuary wetland - A case study of the Yellow River Delta Natural Reserve. Environ. Monit. Assess. 186, 7211-7232.

47. Yang, Z.F., Qin, Y., Yang, W., 2013. Assessing and classifying plant-related ecological risk under water management scenarios in China's Yellow River Delta Wetlands. J. Environ. Manag. 130, 276-287.

48. You, K., Ma, C.H., Gao, H.W., Li, F.Q., Wang, B., 2009. Study on environmental variation and management in Jiaozhou Bay. Mar. Environ. Sci. 28, 34-51(in Chinese).

49. Zhai S.J, Hu W.P., Zhu Z.C., 2010. Ecological impacts of water transfers on Lake Taihu from the Yangtze River, China. Ecol. Eng. 36, 406-420. 